\title{
Von Willebrand factor, ADAMTS13 and mortality in dialysis patients
}

\author{
Gurbey Ocak ${ }^{1,2,3^{*}}$, Mark Roest ${ }^{4}$, Marianne C. Verhaar ${ }^{2}$, Maarten B. Rookmaaker ${ }^{2}$, Peter J. Blankestijn², \\ Willem Jan W. Bos ${ }^{1,5}$, Rob Fijnheer ${ }^{6}$, Nathalie C. Péquériaux ${ }^{7}$ and Friedo W. Dekker ${ }^{3}$
}

\begin{abstract}
Background: Von Willebrand Factor (VWF) multimers are cleaved into smaller and less coagulant forms by the metalloprotease ADAMTS13. The aim of this study was to investigate the association between WWF and ADAMTS13 and mortality in dialysis patients.

Methods: We prospectively followed 956 dialysis patients. WWF levels and ADAMTS13 activity were measured. Cox proportional hazard analyses were used to calculate hazard ratios (HRs) with $95 \%$ confidence intervals (Cls) to investigate the association between quartiles of WWF levels and ADAMTS13 activity and all-cause mortality. HRs were adjusted for age, sex, body mass index, cardiovascular disease, dialysis modality, primary kidney disease, use of antithrombotic medication, systolic blood pressure, albumin, C-reactive protein and residual GFR.

Results: Of the 956 dialysis patients, 288 dialysis patients died within three years (mortality rate 151 per 1000 person-years). The highest quartile of WWF as compared with lower levels of WWF was associated with a 1.4-fold (95\%Cl 1.1-1.8) increased mortality risk after adjustment. The lowest quartile of ADAMTS13 activity as compared with other quartiles was associated with a 1.3-fold (95\%Cl 1.0-1.7) increased mortality risk after adjustment. The combination of the highest WWF quartile and lowest ADAMTS13 quartile was associated with a 2.0-fold (95\%Cl 1.33.0) increased mortality risk as compared with the combination of the lowest WWF quartile and highest ADAMTS13 quartile.
\end{abstract}

Conclusions: High WWF levels and low ADAMTS13 activity were associated with increased mortality risks in dialysis patients.

Keywords: Dialysis, Von Willebrand Factor, ADAMTS13, Mortality, Epidemiology

\section{Background}

Von Willebrand Factor (VWF) is an important protein for platelet function [1,2]. Furthermore, VWF carries factor VIII and protects factor VIII from degradation $[1,2]$. VWF is mainly produced in endothelial cells and the activity of VWF depends largely on its multimer size. The activity of VWF increases with the

\footnotetext{
* Correspondence: G.Ocak@antoniusziekenhuis.n

'Department of Internal Medicine, Sint Antonius Hospital, Nieuwegein, the Netherlands

${ }^{2}$ Department of Nephrology and Hypertension, University Medical Center Utrecht, Utrecht, the Netherlands

Full list of author information is available at the end of the article
}

multimer size. VWF is cleaved in the circulation by ADAMTS13, which converts large VWF multimers into smaller portions [3, 4]. The combination of a low ADAMTS13 activity with a high concentration of VWF is likely to be prothrombotic with an increased risk of cardiovascular diseases and death. In addition, a severe deficiency of ADAMTS13 could lead to thrombotic thrombocytopenic purpura (TTP), which is a potentially fatal thrombotic disorder [5].

In the general population, increased VWF and decreased ADAMTS13 have been associated with myocardial infarction [6-9] and ischemic stroke, [10-13]

(c) The Author(s). 2021 Open Access This article is licensed under a Creative Commons Attribution 4.0 International License, which permits use, sharing, adaptation, distribution and reproduction in any medium or format, as long as you give appropriate credit to the original author(s) and the source, provide a link to the Creative Commons licence, and indicate if changes were made. The images or other third party material in this article are included in the article's Creative Commons licence, unless indicated otherwise in a credit line to the material. If material is not included in the article's Creative Commons licence and your intended use is not permitted by statutory regulation or exceeds the permitted use, you will need to obtain permission directly from the copyright holder. To view a copy of this licence, visit http://creativecommons.org/licenses/by/4.0/ The Creative Commons Public Domain Dedication waiver (http://creativecommons.org/publicdomain/zero/1.0/) applies to the data made available in this article, unless otherwise stated in a credit line to the data. 
probably by inducing a prothrombotic tendency [14]. Two previous studies found that increased VWF levels were associated with increased mortality risks in dialysis patients $[15,16]$. In our cohort, we previously showed that the highest quartile of VWF levels were associated with an 1.8-fold increased mortality risk as compared with the lowest quartile of VWF levels [15]. Another cohort study including 55 dialysis patients showed a 2.6fold increased mortality risk for each one-point increment in VWF levels in IU/ml [16]. However, these studies did not investigate the association between mortality and ADAMTS13 or the combination of ADAMTS13 and VWF. There is only limited information about the combination of increased VWF and decreased ADAM TS13 and the association with all-cause and causespecific mortality (cardiovascular and non-cardiovascular outcomes). One previous population-based cohort study among individuals aged $\geq 55$ years showed that patients with the highest quartile of VWF levels and the lowest quartile of ADAMTS13 levels had a 1.6-fold increased mortality risk as compared with patients with the lowest quartile of VWF levels and the highest quartile of ADAMTS13.[17] In the dialysis population, it is not known whether VWF and ADAMTS13 are associated with all-cause and cause-specific (cardiovascular and non-cardiovascular) mortality.

Dialysis patients have a prothrombotic tendency and have highly increased mortality risks [18]. The investigation of ADAMTS13 and VWF could be of clinical relevance for several reasons. There has been a debate on the effectiveness of vitamin $\mathrm{K}$ antagonist in dialysis patients with atrial fibrillation $[19,20]$. It could be that patients with low ADAMTS13 levels and high VWF levels reflecting highly prothrombotic patients may benefit from antithrombotic therapy.

The aim of this study was to investigate the association between all-cause and cause-specific (cardiovascular and non-cardiovascular) mortality for VWF and ADAMTS13 in dialysis patients.

\section{Methods}

\section{Study population}

NECOSAD (Netherlands Cooperative Study on the Adequacy of Dialysis) is a multicenter, prospective cohort study, in which 38 dialysis centers throughout the Netherlands participated. Incident chronic hemodialysis and peritoneal dialysis patients were included between 1997 and 2007 if they were $\geq 18$ years and had no previous kidney replacement therapy. For this study, we only included patients twelve months after the start of dialysis. Patients were followed till the time of death or censored due to kidney transplantation or loss to follow-up or until March 2010. The study was approved by all local medical ethics committees and all patients gave written informed consent.

\section{Demographic and clinical data}

Data on age, sex, body mass index and primary kidney disease were collected at the start of dialysis treatment. Primary kidney disease was classified according to the codes of the European Renal Association-European Dialysis and Transplant Association (ERA-EDTA) [21]. We grouped patients into seven classes of primary kidney disease: glomerulonephritis, interstitial nephritis, cystic kidney disease, renal vascular disease, diabetes mellitus, multisystem disease and other kidney diseases. Data on comorbidities, use of antithrombotic medication (vitamin $\mathrm{K}$ antagonists or antiplatelet drugs), smoking, blood pressure and laboratory data were collected at twelve months after the start of dialysis, which was defined as baseline. C-reactive protein (CRP), albumin, urea and creatinine were routinely measured in the dialysis centers at twelve months after start of dialysis. Residual glomerular filtration rate (GFR) was calculated as the mean of creatinine and urea clearance corrected for body surface area $(\mathrm{ml} / \mathrm{min}$ per $1.73 \mathrm{~m} 2)$. Von Willebrand factor levels and ADAMTS13 activity were measured twelve months after the start of dialysis using in house enzyme-linked immunosorbent assays in blood sampled before a dialysis session. Polyclonal rabbit antihuman VWF antibodies were used for catching and tagging (DakoCytomation, Glostrup, Denmark). ADAMTS13 activity was measured in a kinetic assay with the Fluorescence Resonance Energy Transfer Substrate VWF 73.

\section{Mortality}

Causes of death were classified according to the ERAEDTA codes, which is a standardized classification of death causes in dialysis patients [21]. Death causes were grouped into cardiovascular and non-cardiovascular mortality. Cardiovascular mortality was defined as death due to myocardial ischemia and infarction (code 11), cardiac arrest/sudden death (code 15), cardiac failure/ fluid overload/pulmonary edema (codes 14,16,18), hyperkalemia/hypokalemia (code 12,17), pulmonary embolism (code 21), stroke (code 22), hemorrhage from ruptured vascular aneurysm (code 26), mesenteric infarction (code 29) and cause of death uncertain/unknown (code 0). All other deaths were defined as noncardiovascular mortality.

\section{Statistical analysis}

Continuous variables are presented as median and interquartile range (IQR). Categorical variables are presented as percentages. Patients were categorized based on quartiles of VWF levels and ADAMTS13 activity. Hazard ratios (HRs) with $95 \%$ confidence intervals (95\% CIs) for 
all-cause and cause-specific mortality within three years of follow-up were calculated using Cox proportional hazard regression analysis. Hazard ratios with $95 \%$ CIs were calculated for the highest quartile of VWF levels as compared with the other quartiles. Furthermore, hazard ratios with $95 \%$ Cis were calculated for the lowest quartile of ADAMTS13 activity as compared with the other quartiles. To investigate the association between the combination of VWF levels and ADAMTS13 activity, we calculated hazard ratios with $95 \%$ CIs for the combination of the highest VWF quartile $(\mathrm{p}>75)$ and lowest ADAMTS13 activity quartile $(\mathrm{p} \leq 25)$ as compared with other combinations of VWF quartiles and ADAMTS13 quartiles. In a sensitivity analysis, we stratified the results for hemodialysis and peritoneal dialysis patients.

Hazard ratios were adjusted for age, sex, body mass index, cardiovascular disease, smoking, dialysis modality, primary kidney disease, use of antithrombotic medication, systolic blood pressure, albumin and CRP levels and residual GFR. To account for missing data of body mass index, albumin and CRP levels and residual GFR, missing values were imputed ten times using the fully conditional specification [22-25]. All analyses have been done in SPSS statistical software version 23.0 (IBM SPSS Statistics).

\section{Results}

\section{Baseline characteristics}

Baseline characteristics of the 956 dialysis patients are shown in Table 1. The median age was 62.9 years, $40.2 \%$ were female, $15.4 \%$ had diabetes mellitus as primary kidney disease and $41.1 \%$ used antithrombotic medication (vitamin $\mathrm{K}$ antagonists or antiplatelet drugs). The mean VWF was $20.5 \mathrm{ug} / \mathrm{ml}$ and the mean activity of ADAMTS13 was $40.9 \%$. Supplemental Table 1 shows the baseline characteristics stratified for VWF quartiles and supplemental Table 2 shows the baseline characteristics stratified for ADAMTS13 quartiles. Patients with highest quartile of VWF or lowest quartile of ADAM TS13 had an increased age, cardiovascular disease, diabetes mellitus and an increased CRP as compared with highest quartile of VWF or lowest quartile of ADAM TS13, respectively. During a mean follow-up of 2.0 years, 288 dialysis patients died within three years (mortality rate 151 per 1000 person-years).

\section{Von Willebrand factor quartiles and mortality}

The mean level of VWF was $36.2 \mathrm{ug} / \mathrm{ml}$ in the highest quartile of VWF and $9.4 \mathrm{ug} / \mathrm{mL}$ in the lowest quartile. Figure 1 shows the inverted Kaplan-Meier survival curves of VWF quartiles for mortality within three years. The cumulative incidence of mortality increased with increasing VWF levels. The cumulative incidence of mortality after three years was $26.6 \%$ for the lowest VWF quartile and $48.4 \%$ for the highest VWF quartile. The
Table 1 Baseline characteristics

\begin{tabular}{|c|c|c|}
\hline \multirow[b]{2}{*}{ Age in years } & \multicolumn{2}{|c|}{ Total $(N=956)$} \\
\hline & 62.9 & $(51.0-72.3)$ \\
\hline Female sex & 384 & $(40.2 \%)$ \\
\hline Body mass index ${ }^{a}\left(\mathrm{~kg} / \mathrm{m}^{2}\right)$ & 24.5 & $(22.3-27.2)$ \\
\hline Systolic blood pressure $(\mathrm{mmHg})$ & 141 & $(129-155)$ \\
\hline Cardiovascular disease & 343 & $(35.9 \%)$ \\
\hline Smoking & 210 & $(22.0 \%)$ \\
\hline Antithrombotic medication & 393 & $(41.1 \%)$ \\
\hline Antiplatelet agents & 234 & $(24.5 \%)$ \\
\hline Anticoagulant drugs & 153 & $(16.0 \%)$ \\
\hline Both & 6 & $(0.6 \%)$ \\
\hline \multicolumn{3}{|l|}{ Dialysis modality } \\
\hline Hemodialysis & 685 & $(71.7 \%)$ \\
\hline Peritoneal dialysis & 271 & $(28.3 \%)$ \\
\hline \multicolumn{3}{|l|}{ Primary Kidney Disease } \\
\hline Glomerulonephritis & 133 & $(13.9 \%)$ \\
\hline Interstitial nephritis & 109 & $(11.4 \%)$ \\
\hline Cystic kidney disease & 114 & $(11.9 \%)$ \\
\hline Vascular disease & 175 & $(18.3 \%)$ \\
\hline Diabetes mellitus & 147 & $(15.4 \%)$ \\
\hline Multisystem disease & 63 & $(6.6 \%)$ \\
\hline Other & 501 & $(52.4 \%)$ \\
\hline Residual GFR (ml/min) & 1.9 & $(0.6-3.7)$ \\
\hline Albumin ${ }^{c}(g / L)$ & 37 & $(33-40)$ \\
\hline C-reactive protein $^{\mathrm{d}}(\mathrm{mg} / \mathrm{L})$ & 6 & $(3-15)$ \\
\hline
\end{tabular}

${ }^{a}$ Missing in 18 patients

${ }^{\mathrm{b}}$ Missing in 187 patients

cMissing in 29 patients

${ }^{\mathrm{d}}$ Missing in 338 patients

highest quartile of VWF as compared with lower levels of VWF was associated with a 1.4-fold (95\%CI 1.1-1.8) increased mortality risk after adjustment for age, sex, body mass index, cardiovascular disease, smoking, dialysis modality, primary kidney disease, use of antithrombotic medication, systolic blood pressure, albumin levels, CRP levels and residual GFR (Table 2). The highest quartile of VWF as compared with lower levels of VWF was associated with a 1.3 -fold (95\% CI 0.9-1.9) increased cardiovascular mortality risk and a 1.5 -fold (95\% CI 1.0-2.2) increased non-cardiovascular mortality risk after adjustment.

\section{ADAMTS13 quartiles and mortality}

The mean activity of ADAMTS13 was $16.7 \%$ in the lowest quartile of ADAMTS13 and $68.1 \%$ in the highest quartile of ADAMTS13. Figure 2 shows the inverted Kaplan-Meier survival curves of ADAMTS quartiles for mortality within three years. The cumulative incidence of mortality was highest for the lowest ADAMTS13 


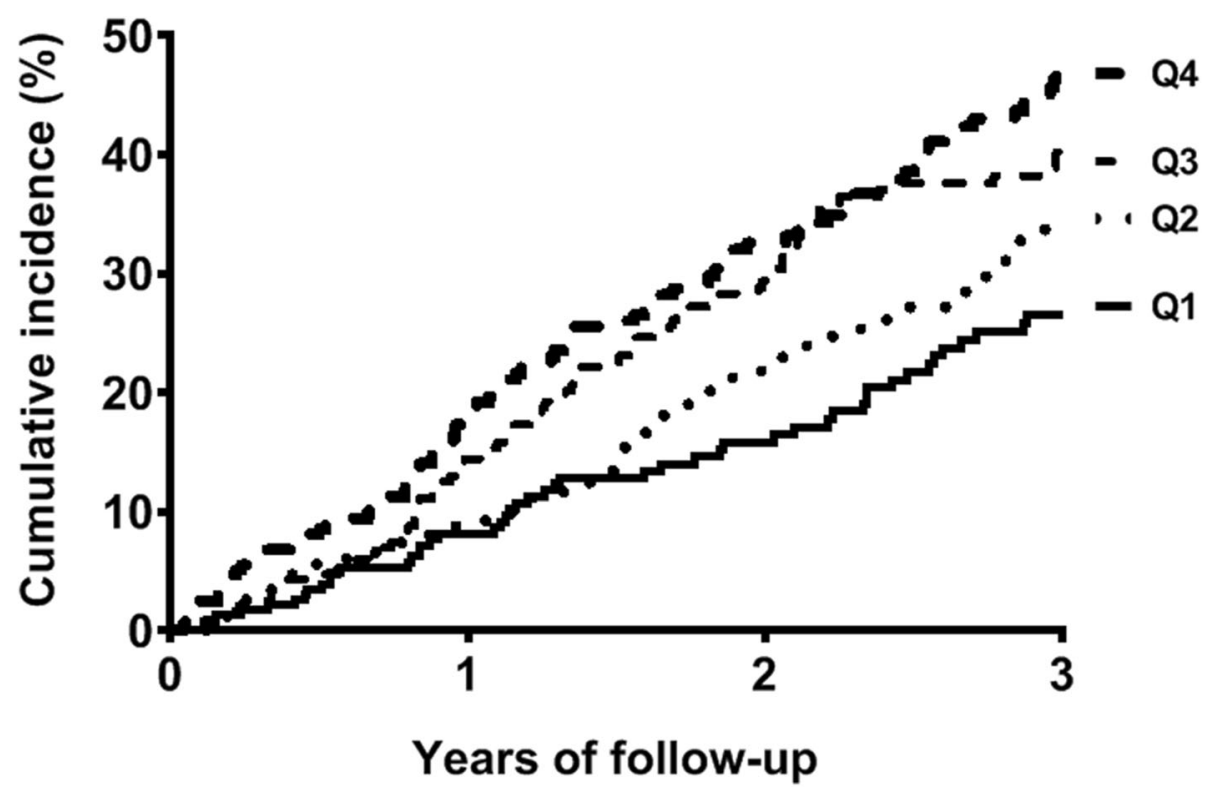

Fig. 1 Kaplan-Meier survival curves for Von Willebrand factor quartiles

Table 2 Von Willebrand factor quartiles and mortality

\begin{tabular}{|c|c|c|c|c|c|c|c|}
\hline All-cause mortality & $\begin{array}{l}\text { Total } \\
N=956\end{array}$ & Mean level (ug/mL) & $\begin{array}{l}\text { Mortality rate per } \\
1000 \text { patient years }\end{array}$ & \multicolumn{2}{|c|}{$\begin{array}{l}\text { Crude } \\
\text { HR }(95 \% \mathrm{Cl})\end{array}$} & \multicolumn{2}{|c|}{$\begin{array}{l}\text { Adjusted }^{\mathrm{a}} \\
\text { HR }(95 \% \mathrm{Cl})\end{array}$} \\
\hline Quartile 1 & 239 & 9.4 & 99 & refer & & refere & \\
\hline Quartile 2 & 239 & 15.4 & 129 & 1.3 & $(0.9-1.9)$ & 1.2 & $(0.8-1.7)$ \\
\hline Quartile 3 & 239 & 21.0 & 172 & 1.7 & $(1.2-2.5)$ & 1.5 & $(1.1-2.2)$ \\
\hline Quartile 4 & 239 & 36.2 & 209 & 2.1 & $(1.5-3.0)$ & 1.8 & $(1.2-2.6)$ \\
\hline Quartile 4 versus Quartile 1-3 & & & & 1.6 & $(1.2-2.0)$ & 1.4 & $(1.1-1.8)$ \\
\hline \multicolumn{8}{|l|}{ Cardiovascular mortality } \\
\hline Quartile 1 & 239 & 9.4 & 51 & refer & & refer & \\
\hline Quartile 2 & 239 & 15.4 & 73 & 1.4 & $(0.8-2.3)$ & 1.3 & $(0.8-2.1)$ \\
\hline Quartile 3 & 239 & 21.0 & 82 & 1.6 & $(1.0-2.6)$ & 1.4 & $(0.9-2.4)$ \\
\hline Quartile 4 & 239 & 36.2 & 102 & 2.0 & $(1.2-3.3)$ & 1.7 & $(1.0-2.8)$ \\
\hline Quartile 4 versus Quartile 1-3 & & & & 1.5 & $(1.1-2.1)$ & 1.3 & $(0.9-1.9)$ \\
\hline \multicolumn{8}{|l|}{ Non-cardiovascular mortality } \\
\hline Quartile 1 & 239 & 9.4 & 47 & refer & & refer & \\
\hline Quartile 2 & 239 & 15.4 & 56 & 1.2 & $(0.7-2.1)$ & 1.1 & $(0.6-1.9)$ \\
\hline Quartile 3 & 239 & 21.0 & 90 & 1.9 & $(1.2-3.2)$ & 1.6 & $(1.0-2.8)$ \\
\hline Quartile 4 & 239 & 36.2 & 107 & 2.3 & $(1.4-3.7)$ & 1.9 & $(1.1-3.3)$ \\
\hline Quartile 4 versus Quartile 1-3 & & & & 1.7 & $(1.2-2.4)$ & 1.5 & $(1.0-2.2)$ \\
\hline
\end{tabular}

${ }^{a}$ Adjusted for age, sex, body mass index, cardiovascular disease, dialysis modality, smoking, primary kidney disease, use of antithrombotic medication, systolic blood pressure, albumin, C-reactive protein and residual GFR 


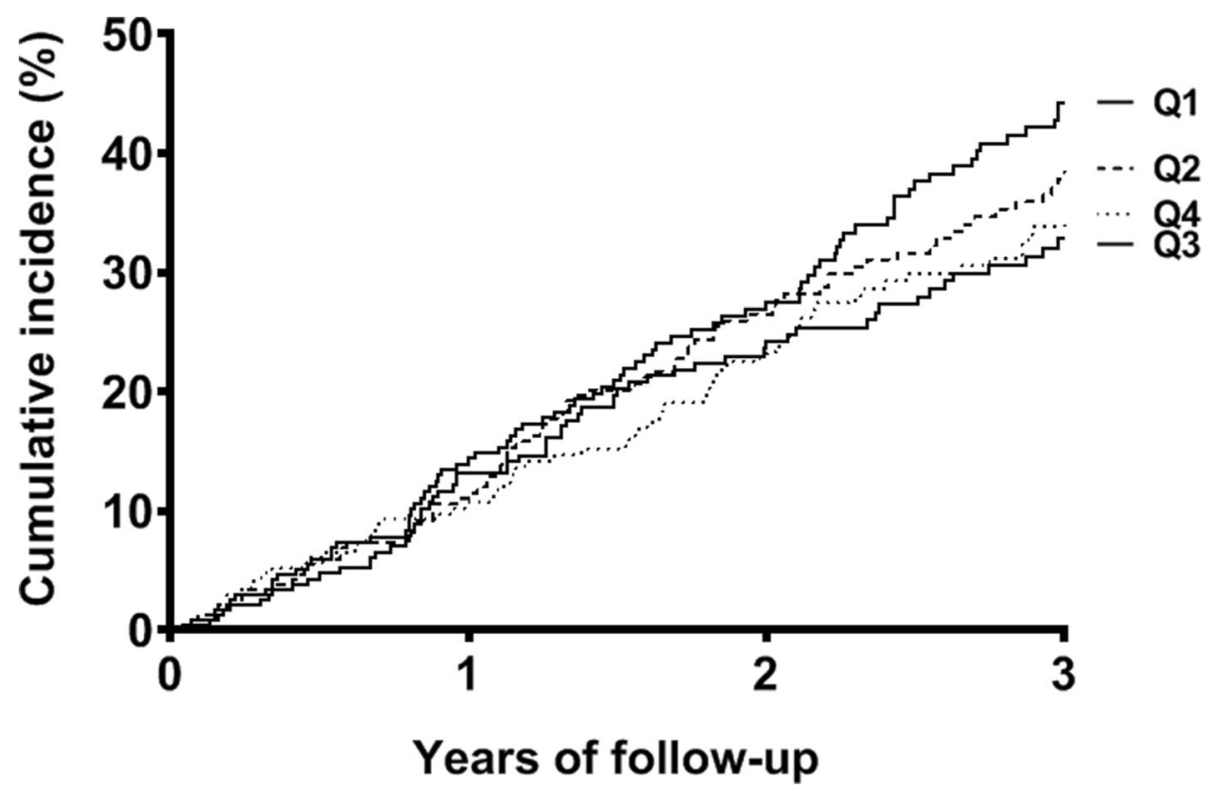

Fig. 2 Kaplan-Meier survival curves for ADAMTS13 quartiles

quartile (44.2\%) and lowest for the highest ADAMTS13 quartile (34.6\%). The lowest quartile of ADAMTS13 as compared with higher quartiles of ADAMTS13 was associated with a 1.3-fold (95\%CI 1.0-1.7) increased mortality risk after adjustment (Table 3 ). The lowest quartile of ADAMTS13 as compared with higher levels of ADAMTS13 was associated with a 1.2-fold (95\% CI $0.9-1.8)$ increased cardiovascular mortality risk and a 1.4-fold (95\% CI 1.0-2.0) increased non-cardiovascular mortality risk after adjustment.

Table 3 ADAMTS13 quartiles and mortality

\begin{tabular}{|c|c|c|c|c|c|c|c|}
\hline All-cause mortality & $\begin{array}{l}\text { Total } \\
N=956\end{array}$ & Mean level (activity \%) & $\begin{array}{l}\text { Mortality rate per } \\
1000 \text { patient years }\end{array}$ & \multicolumn{2}{|c|}{$\begin{array}{l}\text { Crude } \\
\text { HR }(95 \% \mathrm{Cl})\end{array}$} & \multicolumn{2}{|c|}{$\begin{array}{l}\text { Adjusted }^{\mathrm{a}} \\
\text { HR }(95 \% \mathrm{Cl})\end{array}$} \\
\hline Quartile 1 & 239 & 16.7 & 181 & 1.3 & $(1.0-1.8)$ & 1.2 & $(0.9-1.7)$ \\
\hline Quartile 2 & 239 & 33.0 & 156 & 1.1 & $(0.8-1.6)$ & 0.9 & $(0.7-1.3)$ \\
\hline Quartile 3 & 239 & 45.7 & 132 & 1.0 & $(0.7-1.4)$ & 0.9 & $(0.6-1.2)$ \\
\hline Quartile 4 & 239 & 68.1 & 136 & \multicolumn{2}{|c|}{ reference } & \multicolumn{2}{|c|}{ reference } \\
\hline Quartile 1 versus Quartile 2-4 & & & & 1.3 & $(1.1-1.7)$ & 1.3 & $(1.0-1.7)$ \\
\hline \multicolumn{8}{|l|}{ Cardiovascular mortality } \\
\hline Quartile 1 & 239 & 16.7 & 88 & 1.2 & $(0.8-1.8)$ & 1.1 & $(0.7-1.8)$ \\
\hline Quartile 2 & 239 & 33.0 & 80 & 1.1 & $(0.7-1.7)$ & 0.9 & $(0.6-1.4)$ \\
\hline Quartile 3 & 239 & 45.7 & 63 & 0.8 & $(0.5-1.4)$ & 0.8 & $(0.5-1.3)$ \\
\hline Quartile 4 & 239 & 68.1 & 75 & \multicolumn{2}{|c|}{ reference } & \multicolumn{2}{|c|}{ reference } \\
\hline Quartile 1 versus Quartile 2-4 & & & & 1.2 & $(0.9-1.6)$ & 1.2 & (0.9-1.8) \\
\hline \multicolumn{8}{|l|}{ Non-cardiovascular mortality } \\
\hline Quartile 1 & 239 & 16.7 & 92 & 1.5 & $(1.0-2.4)$ & 1.3 & $(0.8-2.2)$ \\
\hline Quartile 2 & 239 & 33.0 & 76 & 1.3 & $(0.8-2.0)$ & 1.0 & $(0.6-1.6)$ \\
\hline Quartile 3 & 239 & 45.7 & 69 & 1.1 & $(0.7-1.9)$ & 1.0 & $(0.6-1.6)$ \\
\hline Quartile 4 & 239 & 68.1 & 61 & \multicolumn{2}{|c|}{ reference } & \multicolumn{2}{|c|}{ reference } \\
\hline Quartile 1 versus Quartile 2-4 & & & & 1.4 & $(1.0-1.9)$ & 1.4 & $(1.0-2.0)$ \\
\hline
\end{tabular}

${ }^{a}$ Adjusted for age, sex, body mass index, cardiovascular disease, smoking, dialysis modality, primary kidney disease, use of antithrombotic medication, systolic blood pressure, albumin, C-reactive protein and residual GFR 


\section{Combination of ADAMTS13 and von Willebrand factor and mortality}

In patients with both high VWF levels (highest quartile, $\mathrm{p} \geq 75$ ) and low ADAMTS13 activity (lowest quartile, $\mathrm{p} \leq 25$ ), the risk of all-cause mortality (HR 2.0; $95 \%$ CI 1.3-3.0) was increased compared with low VWF levels (lowest quartile, $\mathrm{p}<75$ ) and high ADAMTS13 activity (highest quartile, $\mathrm{p}>25$ ) after adjustment (Table 4). High VWF levels and low ADAMTS13 activity as compared with low VWF levels and high ADAMTS13 activity were associated with a 1.8-fold (95\% CI 1.0-3.2) increased cardiovascular mortality risk and a 2.1 -fold $(95 \% \mathrm{CI}$ 1.2-3.7) increased non-cardiovascular mortality risk.

\section{Sensitivity analysis}

As a sensitivity analysis, we calculated HRs stratified for hemodialysis and peritoneal dialysis. In hemodialysis patients, the highest quartile of VWF as compared with lower levels of VWF was associated with a 1.5-fold (95\%CI 1.1-2.0) increased mortality risk and the lowest quartile of ADAMTS13 as compared with higher quartiles of ADAMTS13 was associated with a 1.3-fold (95\%CI 1.0-1.8) increased mortality risk after adjustment. High VWF levels and low ADAMTS13 activity as compared with low VWF levels and high ADAMTS13 activity were associated with a 2.2 -fold (95\% CI 1.4-3.5) increased mortality risk in hemodialysis patients. In peritoneal dialysis patients, risk estimates for the highest quartile of VWF (HR 1.3, $95 \%$ CI 0.7-2.3), lowest quartile of ADAMTS13 (HR 1.4, 95\% CI 0.7-2.5) and the combination of high VWF levels and low ADAMTS13 activity (HR 1.7, $95 \%$ CI $0.7-4.3$ ) were increased, but did not reach statistical significance.

\section{Discussion}

In this prospective cohort study of 956 incident dialysis patients, increased VWF levels and decreased ADAM TS13 activity were associated with an increased risk of mortality. We found a 1.4-fold increased all-cause mortality risk for the highest quartile of VWF as compared with lower levels of VWF and a 1.3-fold increased mortality risk for the lowest quartile of ADAMTS13 activity as compared with other quartiles. The mortality rates were increased for both cardiovascular and noncardiovascular causes. We found the highest mortality rates for patients who had both high VWF levels and low ADAMTS13 activity. The combination of the highest VWF quartile and lowest ADAMTS13 quartile was associated with a 2.0-fold increased mortality risk as compared with the combination of the lowest VWF quartile and highest ADAMTS13 quartile.

In the general population, most previous studies focused on the association between VWF, ADAMTS13 and non-fatal cardiovascular outcomes (myocardial infarction [6-9] or stroke [10-13]). In a meta-analysis that investigated the association between VWF, ADAMTS13 and cardiovascular outcomes, [14] most of the studies found an increased risk of myocardial infarction or stroke. Risk estimates for increased VWF levels ranged from a 0.9 -fold to a 4.7-fold increased risk of myocardial infarction and ranged from a 1.0-fold to a 6.7-fold increased risk of stroke. Risk estimates for decreased

Table 4 Combination of ADAMTS13 and von Willebrand factor and mortality

\begin{tabular}{|c|c|c|c|c|c|c|}
\hline \multirow{2}{*}{ All-cause mortality } & \multirow[t]{2}{*}{$\begin{array}{l}\text { Total } \\
N=956\end{array}$} & $\begin{array}{l}\text { Mortality rate per } \\
1000 \text { patient years }\end{array}$ & \multicolumn{2}{|c|}{$\begin{array}{l}\text { Crude } \\
\text { HR }(95 \% \text { Cl) }\end{array}$} & \multicolumn{2}{|c|}{$\begin{array}{l}\text { Adjusted }^{\mathrm{a}} \\
\text { HR }(95 \% \mathrm{Cl})\end{array}$} \\
\hline & & & & & & \\
\hline WWF $p<75$ AND ADAMTS13 p >25 & 549 & 125 & refere & & refere & \\
\hline WWF $p<75$ AND ADAMTS13 $p \leq 25$ & 168 & 159 & 1.3 & $(0.9-1.7)$ & 1.2 & $(0.9-1.7)$ \\
\hline WWF $p \geq 75$ AND ADAMTS13 p>25 & 168 & 197 & 1.6 & $(1.2-2.1)$ & 1.3 & $(1.0-1.8)$ \\
\hline WF $p \geq 75$ AND ADAMTS13 $p \leq 25$ & 71 & 241 & 2.0 & $(1.3-2.9)$ & 2.0 & $(1.3-3.0)$ \\
\hline \multicolumn{7}{|l|}{ Cardiovascular mortality } \\
\hline WWF $p<75$ AND ADAMTS13 $p>25$ & 549 & 65 & refere & & refere & \\
\hline WWF $p<75$ AND ADAMTS13 $p \leq 25$ & 168 & 79 & 1.2 & $(0.8-1.9)$ & 1.2 & $(0.7-1.8)$ \\
\hline WWF $p \geq 75$ AND ADAMTS13 p>25 & 168 & 99 & 1.5 & $(1.0-2.3)$ & 1.2 & $(0.8-1.9)$ \\
\hline WWF $p \geq 75$ AND ADAMTS13 $p \leq 25$ & 71 & 112 & 1.8 & $(1.0-3.1)$ & 1.8 & $(1.0-3.2)$ \\
\hline \multicolumn{7}{|l|}{ Non-cardiovascular mortality } \\
\hline WWF $p<75$ AND ADAMTS13 $p>25$ & 549 & 60 & refere & & refere & \\
\hline WWF $p<75$ AND ADAMTS13 $p \leq 25$ & 168 & 79 & 1.3 & $(0.8-2.1)$ & 1.3 & $(0.8-2.1)$ \\
\hline WWF $p \geq 75$ AND ADAMTS13 p>25 & 168 & 99 & 1.7 & $(1.1-2.5)$ & 1.5 & $(0.9-2.3)$ \\
\hline WWF $p \geq 75$ AND ADAMTS13 $p \leq 25$ & 71 & 128 & 2.2 & $(1.3-3.7)$ & 2.1 & $(1.2-3.7)$ \\
\hline
\end{tabular}

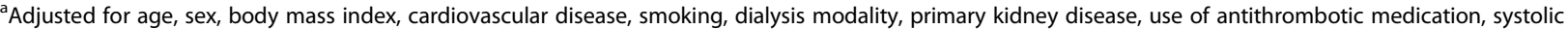
blood pressure, albumin, C-reactive protein and residual GFR 
ADAMTS13 activity ranged from a 0.5-fold to an 8.2fold increased risk of myocardial infarction and ranged from a 1.7-fold to a 7.3-fold increased risk of stroke [14]. The ranges in the risk estimates were wide, probably because of differences in study design and study population of these studies. We also found increased risk estimates of cardiovascular mortality for high VWF levels as compared with low VWF levels (hazard ratio of 1.7) and low ADAMTS13 activity as compared with high ADAMTS13 activity (hazard ratio of 1.2), which is within the range of the previous studies.

Studies investigating the association between all-cause mortality and increased ADAMTS13 activity and decreased VWF levels are limited. One previous study investigated the association between mortality and decreased ADAMTS13 activity and increased VWF levels in the general population [17]. As in our study, the previous study showed increased all-cause mortality risks for high VWF levels and low ADAMTS13 activity. The highest quartile of VWF as compared with the lowest quartile of VWF was associated with a 1.2-fold increased all-cause mortality risk and the lowest quartile of ADAMTS13 as compared with higher quartiles of ADAMTS13 was associated with a 1.5-fold increased mortality risk after adjustment. Furthermore, it was shown that high VWF levels (highest quartile, $\mathrm{p} \geq 75$ ) and low ADAMTS13 activity (lowest quartile, $\mathrm{p} \leq 25$ ) were associated with a 1.6-fold increased all-cause mortality risk as compared with low VWF levels (lowest quartile, $\mathrm{p}<75$ ) and high ADAMTS13 activity (highest quartile, $\mathrm{p}>25$ ) after adjustment, which is in line the 2.0-fold increased risk found in our study. We and others found that increased VWF levels were associated with increased mortality risks in dialysis patients $[15$, 16]. However, these studies did not investigate the association between mortality and ADAMTS13 or the combination of ADAMTS13 and VWF.

An explanation for the associations between mortality and high VWF levels and low ADAMTS13 activity could be a prothrombotic tendency. In a normal situation, VWF multimers are cleaved in the circulation by the metalloprotease ADAMTS13, which converts large VWF multimers into smaller and less procoagulant forms [3, 4]. However, in case of high VWF levels and low ADAM TS13 activity, thrombus formation and thrombus growth could be exaggerated by the prothrombotic tendency. This could eventually lead to an increased cardiovascular mortality risk. Another important note is that in our dialysis population, mean levels of VWF were higher (20.5 $\mathrm{ug} / \mathrm{ml}$ versus $10 \mathrm{ug} / \mathrm{ml}$ ) and mean activity levels of ADAMTS13 were lower $(40.9 \%$ versus $100 \%)$ than in the general population [17]. Also other studies found higher VWF levels and lower ADAMTS13 activity in dialysis patients than non-dialysis patients [26, 27].
Therefore, a prothrombotic tendency could be highly prevalent in dialysis patients. Increased VWF levels and lower ADAMTS13 activity in dialysis patients as compared with the general population could be a reflection of a high prevalence of comorbidities, including cardiovascular diseases and diabetes mellitus. We did not investigate genetic determinants for VWF levels and ADAMTS13 activity. In our study, besides increased risk estimates for cardiovascular mortality, risk estimates were also increased for non-cardiovascular mortality. It could be that VWF and ADAMTS13 are also involved in progression of other diseases than arterial thrombosis (myocardial infarction and stroke) leading to an increased non-cardiovascular mortality. There are some studies showing a role of VWF and ADAMTS13 in pulmonary diseases, [28] sepsis [29, 30] and cancer [31, 32]. The exact mechanisms behind these findings are not known.

The main strength of this study was the large and well-defined prospective cohort of dialysis patients with available data on many patient characteristics and laboratory measurements, which allowed us to investigate the association between VWF, ADAMTS13 and mortality. Another strong point of the study is that all measurements of VWF and ADAMTS13 have been done twelve months after initiation of dialysis. This reduces the risk that measurements were affected by fluctuations commonly observed at the commencement of dialysis in the acute phase. Our study also has several potential limitations. An important limitation in the association between VWF, ADAMTS13 and mortality is the possibility of residual confounding. In our analyses, we took this into account by correcting for multiple confounders, but this cannot exclude possible residual confounding. Therefore, it could be that high VWF and low ADAM TS13 are markers for other underlying diseases that we did not adjust for. Another limitation of our study was the limited power in the subgroup analysis with peritoneal dialysis patients. However, risk estimates were more or less similar with hemodialysis patients. Furthermore, we had no information about the type, dose or indication of anticoagulants and antiplatelet agents to investigate the role of these factors in the association between mortality VWF and ADAMTS13. Finally, we could not investigate the association between VWF and ADAM TS13 and mortality in a subgroup of patients with atrial fibrillation, since we had no information about the presence of atrial fibrillation in our cohort. Dialysis patients have highly increased risks of atrial fibrillation [20] and VWF and ADAMTS13 have been associated with worse outcomes in patients with atrial fibrillation [33, 34]. Therefore, atrial fibrillation could play an important role in the association between VWF and ADAMTS13 and mortality in dialysis patients. 
Decreased ADAMTS13 and increased VWF levels are relevant in TTP, which clinically manifests itself as thrombocytopenia, micro-angiopathic hemolytic anemia, fever, neurological symptoms and renal insufficiency due to the formation of microthrombi [5]. Our finding that the combination of increased VWF and decreased ADAMTS13 is associated with an increased mortality risk could also have clinical implications in dialysis patients. There has been a debate on the effectiveness of antithrombotic therapy in dialysis patients, since studies did not show a decreased risk of ischemic stroke in dialysis patients who used vitamin $\mathrm{K}$ antagonists as compared with patients without vitamin $\mathrm{K}$ antagonist use $[19,20]$. Furthermore, ischemic stroke models have weak predictive performances in incident dialysis patients [35]. Patients with low ADAMTS13 levels and high VWF levels reflecting highly prothrombotic patients may be a subgroup of patients who could benefit from antithrombotic therapy.

\section{Conclusions}

In summary, we have shown that increased VWF levels and decreased ADAMTS13 activity were associated with an increased risk of mortality in dialysis patients.

\section{Abbreviations}

WF: Von Willebrand Factor; TTP: Thrombotic thrombocytopenic purpura; GFR: Glomerular filtration rate; CRP: C-reactive protein; ERA-EDTA: European Renal Association-European Dialysis and Transplant Association

\section{Supplementary Information}

The online version contains supplementary material available at https://doi. org/10.1186/s12882-021-02420-z.

Additional file 1: Supplemental Table 1: Baseline characteristics

stratified for Von Willebrand factor quartiles

Additional file 2: Supplemental Table 2: Baseline characteristics stratified for ADAMTS13 quartiles

\section{Acknowledgements}

We thank the investigators and study nurses of the participating dialysis centers and the data managers of the Netherlands Cooperative Study on the Adequacy of Dialysis (NECOSAD) for collection and management of data.

\section{Authors' contributions}

GO and FWD designed the research, acquisition of data and analysis and interpretation of data were done by GO, MR, MCV, MBR, RF, NCP and FWD, GO an FWD drafted the manuscript, MR, MCV, MBR, PJB, WJWB, RF and NCP critically read and revised the manuscript. All authors read and approved the final manuscript.

\section{Funding}

The Netherlands Cooperative Study on the Adequacy of Dialysis was supported in part by an unrestricted grant from the Dutch Kidney Foundation. The funding source was involved in neither the collection, interpretation, and analysis of the data nor the decision for the writing and submission of this report for publication.

\section{Availability of data and materials}

The datasets used and analyzed during the current study are available from the corresponding author on reasonable request.

\section{Declarations}

Ethics approval and consent to participate

The study has conformed to the ethical principles of the Declaration of Helsinki and was approved by the Medical Ethics Committee of the Leiden University Medical Center. And all patients had signed informed consent.

\section{Consent for publication}

Not applicable.

\section{Competing interests}

The authors declare that they have no competing interests.

\section{Author details}

${ }^{1}$ Department of Internal Medicine, Sint Antonius Hospital, Nieuwegein, the Netherlands. ${ }^{2}$ Department of Nephrology and Hypertension, University Medical Center Utrecht, Utrecht, the Netherlands. ${ }^{3}$ Department of Clinical Epidemiology, Leiden University Medical Center, Leiden, the Netherlands. ${ }^{4}$ Synapse Research Institute, Cardiovascular Research Institute, Maastricht, the Netherlands. ${ }^{5}$ Department of Internal Medicine, Leiden University Medical Center, Leiden, the Netherlands. ${ }^{6}$ Department of Internal Medicine, Meander Medical Center, Amersfoort, the Netherlands. ${ }^{7}$ Department of Clinical Chemistry and Hematology, Jeroen Bosch Hospital, 's-Hertogenbosch, the Netherlands.

Received: 11 May 2020 Accepted: 3 June 2021

Published online: 16 June 2021

\section{References}

1. Ruggeri ZM, Ware J. The structure and function of von Willebrand factor. Thromb Haemost. 1992;67(6):594-9.

2. Sadler JE. Biochemistry and genetics of von Willebrand factor. Annu Rev Biochem. 1998:67:395-424.

3. Gerritsen HE, Robles R, Lammle B, et al. Partial amino acid sequence of purified von Willebrand factor-cleaving protease. Blood. 2001;98(6):1654-61.

4. Fujikawa K, Suzuki H, McMullen B, et al. Purification of human von Willebrand factor-cleaving protease and its identification as a new member of the metalloproteinase family. Blood. 2001;98(6):1662-6.

5. Tsai HM. Thrombotic thrombocytopenic purpura: a thrombotic disorder caused by ADAMTS13 deficiency. Hematol Oncol Clin North Am. 2007;21(4): 609-32. v.

6. Crawley JT, Lane DA, Woodward M, et al. Evidence that high von Willebrand factor and low ADAMTS-13 levels independently increase the risk of a non-fatal heart attack. J Thromb Haemost. 2008;6(4):583-8.

7. Kucharska-Newton AM, Couper DJ, Pankow JS, et al. Hemostasis, inflammation, and fatal and nonfatal coronary heart disease: long-term follow-up of the atherosclerosis risk in communities (ARIC) cohort. Arterioscler Thromb Vasc Biol. 2009:29(12):2182-90.

8. Willeit $\mathrm{P}$, Thompson A, Aspelund $\mathrm{T}$, et al. Hemostatic factors and risk of coronary heart disease in general populations: new prospective study and updated meta-analyses. PLoS One. 2013;8(2):e55175.

9. Whincup $\mathrm{PH}$, Danesh J, Walker M, et al. von Willebrand factor and coronary heart disease: prospective study and meta-analysis. Eur Heart J. 2002;23(22): 1764-70.

10. Sonneveld MA, de Maat MP, Portegies ML, et al. Low ADAMTS13 activity is associated with an increased risk of ischemic stroke. Blood. 2015;126(25): 2739-46.

11. van Schie MC, MP DEM, Dippel DW, et al. von Willebrand factor propeptide and the occurrence of a first ischemic stroke. J Thromb Haemost. 2010;8(6): 1424-6.

12. Tzoulaki I, Murray GD, Lee AJ, et al. Relative value of inflammatory, hemostatic, and rheological factors for incident myocardial infarction and stroke: the Edinburgh Artery Study. Circulation. 2007;115(16):2119-27.

13. Andersson HM, Siegerink B, Luken BM, et al. High WWF, low ADAMTS13, and oral contraceptives increase the risk of ischemic stroke and myocardial infarction in young women. Blood. 2012;119(6):1555-60.

14. Sonneveld MA, de Maat MP, Leebeek FW. Von Willebrand factor and ADAM TS13 in arterial thrombosis: a systematic review and meta-analysis. Blood Rev. 2014;28(4):167-78. 
15. Pequeriaux NC, Fijnheer R, Gemen EF, et al. Plasma concentration of von Willebrand factor predicts mortality in patients on chronic renal replacement therapy. Nephrol Dial Transplant. 2012;27(6):2452-7.

16. Holden RM, Tuttle A, Burbidge $T$, et al. Quantitative and qualitative changes of von Willebrand factor and their impact on mortality in patients with endstage kidney disease. Blood Coagul Fibrinolysis. 2013;24(7):719-26.

17. Sonneveld MA, Franco OH, Ikram MA, et al. Von Willebrand Factor, ADAM TS13, and the Risk of Mortality: The Rotterdam Study. Arterioscler Thromb Vasc Biol. 2016;36(12):2446-51.

18. Ocak G, Noordzij M, Rookmaaker MB, et al. Mortality due to bleeding, myocardial infarction and stroke in dialysis patients. J Thromb Haemost. 2018;16(10):1953-63.

19. Van Der Meersch H, De Bacquer D, Vriese AS. Vitamin K antagonists for stroke prevention in hemodialysis patients with atrial fibrillation: A systematic review and meta-analysis. AmHeart J. 2016:184:37-46.

20. Zimmerman D, Sood MM, Rigatto C, et al. Systematic review and metaanalysis of incidence, prevalence and outcomes of atrial fibrillation in patients on dialysis. NephrolDialTransplant. 2012;27(10):3816-22.

21. van Dijk PC, Jager KJ de. C, F., et al. Renal replacement therapy in Europe: the results of a collaborative effort by the ERA-EDTA registry and six national or regional registries. NephrolDialTransplant. 2001;16(6):1120-9.

22. Moons KG, Donders RA, Stijnen T, et al. Using the outcome for imputation of missing predictor values was preferred. J Clin Epidemiol. 2006;59(10): 1092-101.

23. Marshall A, Altman DG, Holder RL, et al. Combining estimates of interest in prognostic modelling studies after multiple imputation: current practice and guidelines. BMC Med Res Methodol. 2009;9:57.

24. Kenward MG, Carpenter J. Multiple imputation: current perspectives. Stat Methods Med Res. 2007;16(3):199-218.

25. de Goeij MC, van Diepen M, Jager KJ, et al. Multiple imputation: dealing with missing data. Nephrol Dial Transplant. 2013;28(10):2415-20.

26. Rios DR, Carvalho MG, Figueiredo RC, et al. ADAMTS13 and Von Willebrand factor in patients undergoing hemodialysis. J Thromb Thrombolysis. 2012; 34(1):73-8.

27. Rios DR, Fernandes AP, Figueiredo RC, et al. Relationship between $A B O$ blood groups and von Willebrand factor, ADAMTS13 and factor VIII in patients undergoing hemodialysis. J Thromb Thrombolysis. 2012;33(4):41621.

28. Polatli M, Cakir A, Cildag O, et al. Microalbuminuria, von Willebrand factor and fibrinogen levels as markers of the severity in COPD exacerbation. J Thromb Thrombolysis. 2008:26(2):97-102.

29. Bongers TN, Emonts M, de Maat MP, et al. Reduced ADAMTS13 in children with severe meningococcal sepsis is associated with severity and outcome. Thromb Haemost. 2010;103(6):1181-7.

30. Kremer Hovinga JA, Zeerleder S, Kessler P, et al. ADAMTS-13, von Willebrand factor and related parameters in severe sepsis and septic shock. J Thromb Haemost. 2007;5(11):2284-90.

31. Hatzipantelis ES, Athanassiou-Metaxa M, Gombakis N, et al. Thrombomodulin and von Willebrand factor: relation to endothelial dysfunction and disease outcome in children with acute lymphoblastic leukemia. Acta Haematol. 2011;125(3):130-5.

32. Morganti M, Carpi A, Amo-Takyi B, et al. Von Willebrand's factor mediates the adherence of human tumoral cells to human endothelial cells and ticlopidine interferes with this effect. Biomed Pharmacother. 2000;54(8-9): 431-6.

33. Roldan V, Marin F, Muina B, et al. Plasma von Willebrand factor levels are an independent risk factor for adverse events including mortality and major bleeding in anticoagulated atrial fibrillation patients. J Am Coll Cardiol. 2011; 57(25):2496-504.

34. Freynhofer MK, Gruber SC, Bruno V, et al. Prognostic value of plasma von Willebrand factor and its cleaving protease ADAMTS13 in patients with atrial fibrillation. Int J Cardiol. 2013;168(1):317-25.

35. de Jong $\mathrm{Y}$, Ramspek $\mathrm{CL}$, van der Endt VHW, et al. A systematic review and external validation of stroke prediction models demonstrates poor performance in dialysis patients. J Clin Epidemiol. 2020;123:69-79.

\section{Publisher's Note}

Springer Nature remains neutral with regard to jurisdictional claims in published maps and institutional affiliations.

\section{Ready to submit your research? Choose BMC and benefit from:}

- fast, convenient online submission

- thorough peer review by experienced researchers in your field

- rapid publication on acceptance

- support for research data, including large and complex data types

- gold Open Access which fosters wider collaboration and increased citations

- maximum visibility for your research: over $100 \mathrm{M}$ website views per year

At BMC, research is always in progress.

Learn more biomedcentral.com/submissions 